\title{
Selecting on the professor? A conjoint experiment on gender and racial bias at the doorway to the political science classroom
}

\author{
Stuart J. Turnbull-Dugarte* \\ A research project completed as part of the Postgraduate Certificate in Academic Practice \\ Centre for Higher Education Practice (University of Southampton) ${ }^{\dagger}$
}

July 7, 2022

\begin{abstract}
A large body of literature demonstrates that woman and racially diverse university instructors are often subjected to systematic discrimination during the teaching evaluation process. In this short paper, I test whether biases against woman and non-white instructors also play a role before students actually enter the classroom by assessing whether students' preferences for elective modules are influenced by the gender or race of the instructor. Leveraging a conjoint experiment among first-year Politics undergraduates at one of the UK's twenty-four leading, Russell Group, universities, and against the expected hypotheses, I find that students' preferences for elective modules are not influenced by the gender or racial profile of the instructor.
\end{abstract}

Keywords: conjoint experiment, discrimination, gender, political science, race, UK Higher Education

\footnotetext{
${ }^{*}$ Assistant Professor, University of Southampton. Email: s.turnbull-dugarte@soton.ac.uk

${ }^{\dagger}$ Ethical approval for experiment described in this study was provided by the University of Southampton's Faculty Ethics Committee. ERGO application ID: 68830.
} 


\section{Introduction}

Biases against faculty in the classroom are commonplace in higher education. Whilst earlier scholarly attention to the issue of bias against women and faculty of colour provided mixed results (Harris, 1975), an expanding cross-disciplinary catalogue of work is increasingly arriving to symmetrical conclusions: women and ethnically diverse professors are subjected to a penalty in evaluations of their instruction (Bascow \& Silberg, 1987; Boring, 2017; Cramer \& Alexitch, 2000; Fan et al., 2019; Martin, 2016; Wagner et al., 2016).

Recent studies that attempt to tease out the effects of bias from confounding influences, such as class size (Martin, 2016) or subject topic (Sampaio, 2006), in the political sciences provide convincing evidence that biases exist independently of these factors. Experimentally manipulating the perceived gender of faceless (online) instructors via variations in (gendered) names shows that, regardless of the instructors actual gender, female-named instructors received significantly lower evaluations (MacNell et al., 2015). Biases against woman working in higher education classrooms in not only observed in ordinal response items where professors are "rated" via easily operationalised scales, but also emerges in open-ended response items. Miller and Chambrlain (2000) find, for example, that among students of sociology, women are more frequently referred to as "teachers" whilst men are more commonly identified as "professors". This change in nomenclature, which from an outsiders' perceptive might seem trivial, is indicative of the biased perception that women in higher education are less qualified that their male peers. Similar findings have been found among students of political science (Mitchell \& Martin, 2018) contributing to wider evidence of gender bias in political science teaching evaluations (Chávez \& Mitchell, 2020; Gelber et al., 2022; Mitchell \& Martin, 2018).

Biases in teaching evaluations are not, however, unique to women. Comparative evidence demonstrates that faculty of colour are also systematically prone to suffer penal- 
ties in student evaluations. Reid (2000), for example, find that the most highly rated faculty on the popular website RateMyProfessor.com were significantly more likely to be white and that the most poorly rated were significantly more likely to be Black or Asian. Even in quasi-experimental settings (in the US) where content, assignments, schedules and instructor-student communications are held constant, political science instructors of colour and women receive significantly lower evaluations than their male and white peers (Chávez \& Mitchell, 2020).

The effect of these biases are not trivial. At times, negative evaluations can impact directly on promotion outcomes (Wagner et al., 2016). On average, women faculty dedicate more of their professional time to teaching as opposed to research (Link et al., 2008). Receiving systematically biased evaluations may increase the incentive to focus on teaching vis-à-vis research, as women are exposed to (biased and erroneous) information that suggests their teaching of a suboptimal quality in comparison to their male counterparts (Mengel et al., 2019). Given the higher education system places a professional premium on research production over teaching, the knock-on effects of gender bias in evaluations may be the prioritisation of objectives that are detrimental to career progression.

Analysing the presence of these biases is often attempted following the delivery of instruction. Whether using observational data, leveraging a quasi-experimental setting, or designing a researcher-led experimental intervention, analysing students' bias against women and faculty of colour relies on assessing post-hoc asymmetries in ordinal evaluation scores or in systematic differences in students' comments. Biases against women and faculty of colour are assumed to be implicit and, therefore, "automatic" and "unintentional" (Peterson et al., 2019). If these biases are implicit, they should exist even before students have actually undertaken instruction.

In this paper, I seek to test for the presence of biases before students enter the classroom. Most undergraduate degree programmes include a combination of core (compulsory) modules and elective (optional) courses. If students are systematically biased 
against women and racially diverse faculty, do these biases influence their choices when selecting elective courses? Empirically, I answer this research question via a conjoint survey experiment of Politics undergraduates in a Russell Group university in the UK. Against the hypotheses of systematic bias, the experiment does not produce evidence to suggest that students select on the professor when opting in to undergraduate electives.

\section{Experiment}

To test the influence of bias in the elective module selection process, I conduct an experiment among the 2021-22 cohort of first year students enrolled in undergraduate degree programmes offered by Department of Politics \& International Relations at the University of Southampton.

\section{Case}

The University of Southampton is a Russell Group University. The Russell Group was formed in 1994 to distinguish "old" research-intensive universities from the more teaching-intensive universities that were established in 1992 after their transition from former polytechnic institutions to degree-granting universities (Boliver, 2015). The Russell Group label, which largely serves as branding devise, allows the groups' twentyfour university members to present themselves as the UK's "leading" institutions or, to use the group's own term, "jewels in the crown" of UK higher education (RussellGroup, 2012). The group's twenty-four members are, however, largely comparable institutions with a long pedigree of experience leading the UK's higher education sector.

The experimental test was fielded among students of only one university (Southampton). In terms of the external validity of the sample of Politics students at Southamp- 


\section{Russell Group Universities compared}
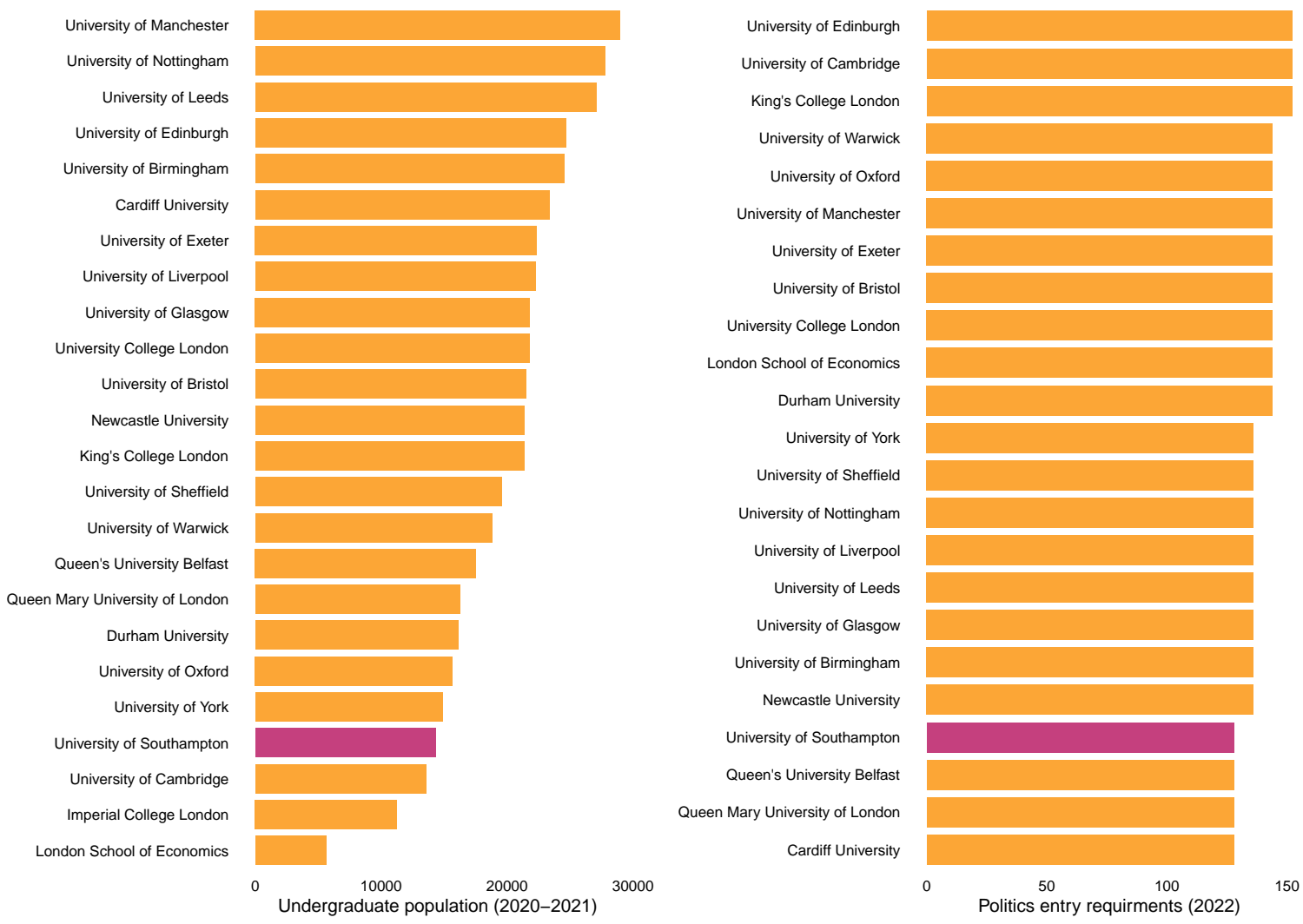

Figure 1: Russell Group Universities

ton, there are a number of indicators that allow me to assess to what extent the sample may be (dis)similar from that of other Politics departments in the UK. In comparison to other Russell Group members, and as visualised in Figure 1, the overall size of Southampton's undergraduate population is slightly lower than the Russell Group median. The University of Southampton has a population similar to that of the University of York or the University of Cambridge. The entry requirements for Southampton's undergraduate Politics degree are below the median (AAB at A-level | 136 UCAS points) at ABB (128 UCAS points). ${ }^{1}$ However, the Complete University Guide and The Guardian University Guide, both frequently used UK university league tables, place Southampton, respectively, 15th and 17th, among UK contemporaries in 2022. ${ }^{2}$ This is

\footnotetext{
${ }^{1}$ A-levels (Advanced levels) are two-years courses that result in standardised externally invigilated assessments administered across schools in England and Wales. Students in post-compulsory education typically take up to three A-level in preparation for university. Resulting A-level grades can be transcribed in UCAS points in order to be compared to other international qualifications. See: https://www.ucas.com/ucas/tariff-calculator

${ }^{2}$ See https://www.theguardian.com/education/ng-interactive/2021/sep/11/ the-best-uk-universities-2022-rankings and https://www.thecompleteuniversityguide.co.uk/
} 
a ranking above the median for the Russell Group. Although league tables should be interpreted with caution (for a discussion, see Turner (2005) and Amsler and Bolsmann (2012)), they are often used by prospective students a source of critical information that inform their choice of institution (Bowden, 2000).

\section{Design}

The research design employed leverages a conjoint survey experiment (Hainmueller et al., 2014) that simultaneously varies elective module characteristics in order to measure how students' multidimensional preferences for distinct modules are influenced by concrete course attributes. Conjoint surveys have a long pedigree in business studies, and are increasingly en vogue in political science. An expanding body of literature has leveraged conjoint experimental designs to test, for example, discrimination against LGBT+ political candidates (Magni \& Reynolds, 2021), the effects of corruption (Breitenstein, 2019) or the efficacy of political endorsements (Christensen et al., 2021) on voter preferences, as well as the role of concrete multidimensional policy provisions in driving support for policy reforms (Bechtel et al., 2017; Gallego \& Marx, 2017).

In this study, I rely on a choice-based conjoint experiment to assess the potential for bias against women and non-white professors in the module selection process. Concretely, individual respondents (students) were presented with a short prompt detailing the activity they were being asked to compete. Subsequently, each student was the presented with six consecutive independent comparisons between two distinct hypothetical elective module designs and asked: i) the elective module they prefer, and ii) the likelihood that they would take each hypothetical elective class. An illustrative image of how the prompt and one of the hypothetical two-course comparisons were presented to students is produced in Figure 2.

The subject matter of the hypothetical courses was held constant (British Politics) but league-tables/rankings 


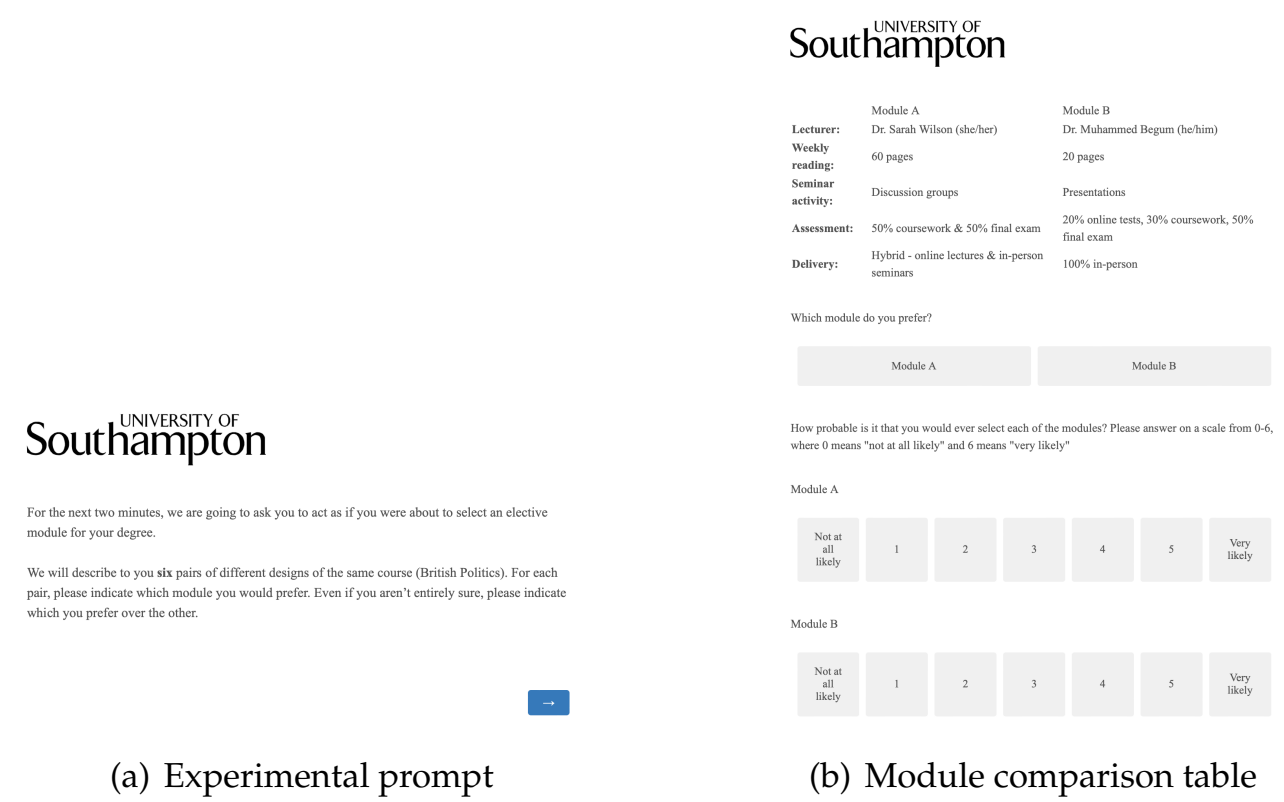

Figure 2: Experimental design

the proposed modules varied on a battery of different characteristics. The attributes and their corresponding values are summarised in Table 1. Module attribute values are simultaneously randomly assigned for each hypothetical module profile, and the order of attributes are randomly assigned between individual respondents. Of theoretical interest to the study at hand are gender and race. Both of these attributes were manipulated via hypothetical gender ${ }^{3}$ and racially typical names. Dr Sarah Wilson (she/her) and Dr John Green (he/him) were, respectively, the female and male variations of the white lecturers. Dr Muhammed Begum (he/him) and Dr Neema Habibi (she/her) were, respectively, the non-white lecturers. Two features of these attribute values are worth further discussion. First, the names used to indicate "non-white" are frequently adopted by Muslims. Muslims have been subjected with widespread discrimination in the UK and British citizens often conflate practicing Islam with nonwhite ethnicity (Donnaloja, 2021), making the name manipulation a consciously direct test of non-white biases. Second, the attributes explicitly presented, alongside the names, the gender pronouns of the lecturers. The use of pronouns is not uncommon

\footnotetext{
${ }^{3}$ The decision to focus on a dichotomous distinction between men and women, as opposed to a more inclusive range of values that incorporates non-binary or gender non-confirming individuals was a design choice driven by power calculations. An increasing number of attribute values necessitates an increasing number of observations (either respondents or conjoint iterations).
} 
Table 1: Conjoint design

\begin{tabular}{ll}
\hline Attribute & Attribute values \\
\hline \multirow{2}{*}{ Lecturer gender } & Man \\
& Woman \\
\hline \multirow{2}{*}{ Lecturer race } & White \\
& Non-white \\
\hline \multirow{3}{*}{ Teaching delivery } & $100 \%$ in-person \\
& $100 \%$ online \\
& Hybrid - Online lectures \& in-person seminars \\
\hline \multirow{3}{*}{ Weekly reading load } & 20 pages/week \\
& 40 pages/week \\
& 60 pages/week \\
\hline \multirow{3}{*}{ Seminar activity } & Data labs/assignments \\
& Discussion groups \\
& Presentations \\
& Varied \\
\hline \multirow{5}{*}{ Assessment architecture } & $100 \%$ coursework \\
& $100 \%$ final exam \\
& Mixed: 20\% tests, 30\% coursework, 50\% final exam \\
\hline
\end{tabular}

in the university where, in a move to be more inclusive, staff are encouraged to include their preferred pronouns on their staff profile on the university webpage as well as in their email signatures.

Given the wealth of literature on bias in higher education teaching evaluations against women and people of colour, including, specifically within political science, the expectation of the design was that students would be significantly less inclined to opt-in to modules instructed by woman (hypotheses 1) or faculty of colour (hypotheses 2). Finally, I anticipate that the gender penalty in preferences for elective modules will be greater for lecturers of colour than white lecturers (hypotheses three).

The experimental design resulted in a dataset $(\mathrm{N}=936)$ where observations represent individual elective module profiles gathered from six forced comparisons presented to a population of 78 students. 


\section{Results}

Figure 3 reports the results of the experiment. The figure reports the average marginal component effect (AMCE) of each of the attribute values. The AMCE is estimated via ordinary least squares (OLS) regression which produces, given the independent randomisation of attribute values, unbiased AMCE estimates (Hainmueller et al., 2014). Visualised coefficients include 95\% confidence intervals from an estimation with standard errors clustered at the individual-level. The AMCE can be interpreted in the percentage-point change in the probability $(0-1)$ that an elective module profile is selected in the forced-choice comparison. An alternative estimation relying on the 7point (0-6) self-reported likelihood of selecting the module outcome measure is reported in appendix Table A2. The results remain unchanged.

On average, students' preferences for elective classes are not influenced by the gender or racial profile of the course professor. The AMCE of gender is marginal $(\beta=.021)$ and insignificant $(p=.558)$. The hypothesised relationship between gender and module selection was negative: i.e. modules led by woman lecturers would suffer a penalty in the elective module selection process. The positively-signed (yet insignificant) AMCE for gender is in direct opposition to this expectation. The AMCE for race, whilst negatively-signed as expected, indicates a null effect. The AMCE $(\beta=-.019)$ is of a similar, marginal, magnitude to gender and is far from indistinguishable from zero $(p=.584)$. These null effects indicate that, on average, students elective course preferences are not significantly shaped by gender or racial biases. In other words, there is no evidence that students select on the professor.

A comparison of the marginal role of gender and race can be demonstrated by comparing the substantive effect of these variables to those of conventional course characteristics. Given the categorical nature of attribute values in the conjoint design, the relative influence of attribute AMCEs are directly comparable. The negative (yet insignificant) AMCE of race is dwarfed by the sizeable and significant effect of teaching 


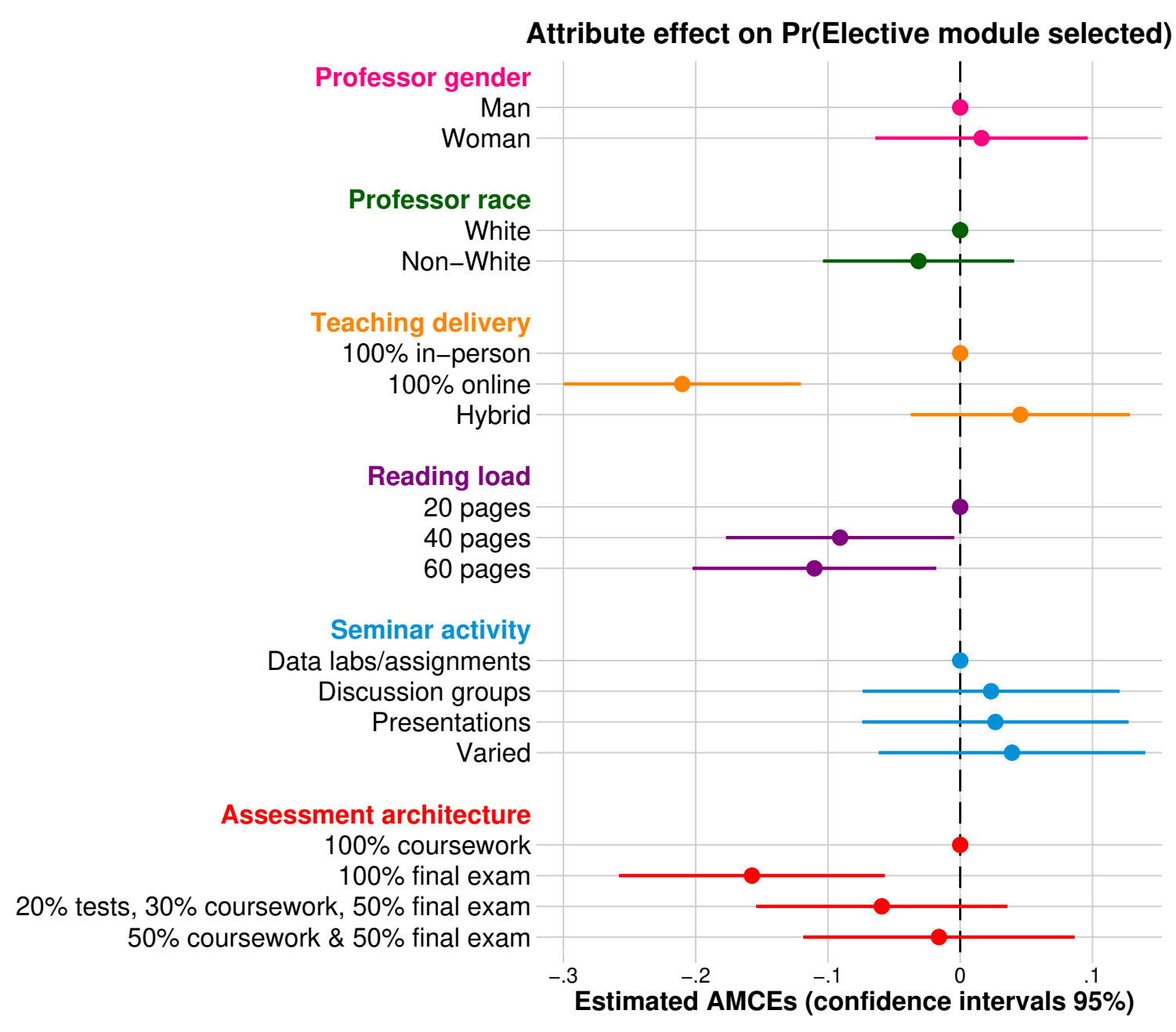

Figure 3: Average marginal component effects

delivery. Elective courses that are delivered online experience a 20 percentage-point drop in the probability of being preferred $(\beta=-.199 \mid p<.001)$ which is an effect more than ten times the magnitude of the (insignificant) AMCE of either race or gender. A similarly large effect is observed in the case of weekly reading loads: electives with a 40-page load are 11 percentage-points less preferred than modules with a 20page load $(\beta=-.109 \mid p<.01)$. These substantive and significant effects indicate that, students care far more about core characterises of elective modules rather than the gender or racial profile of the individual that will deliver the course.

To test hypothesis 3 regarding the potential for asymmetric gender penalties based on the race of the lecturer in the elective modules, I estimate the average component 


\section{Intersectionality of gender \& race}

.6

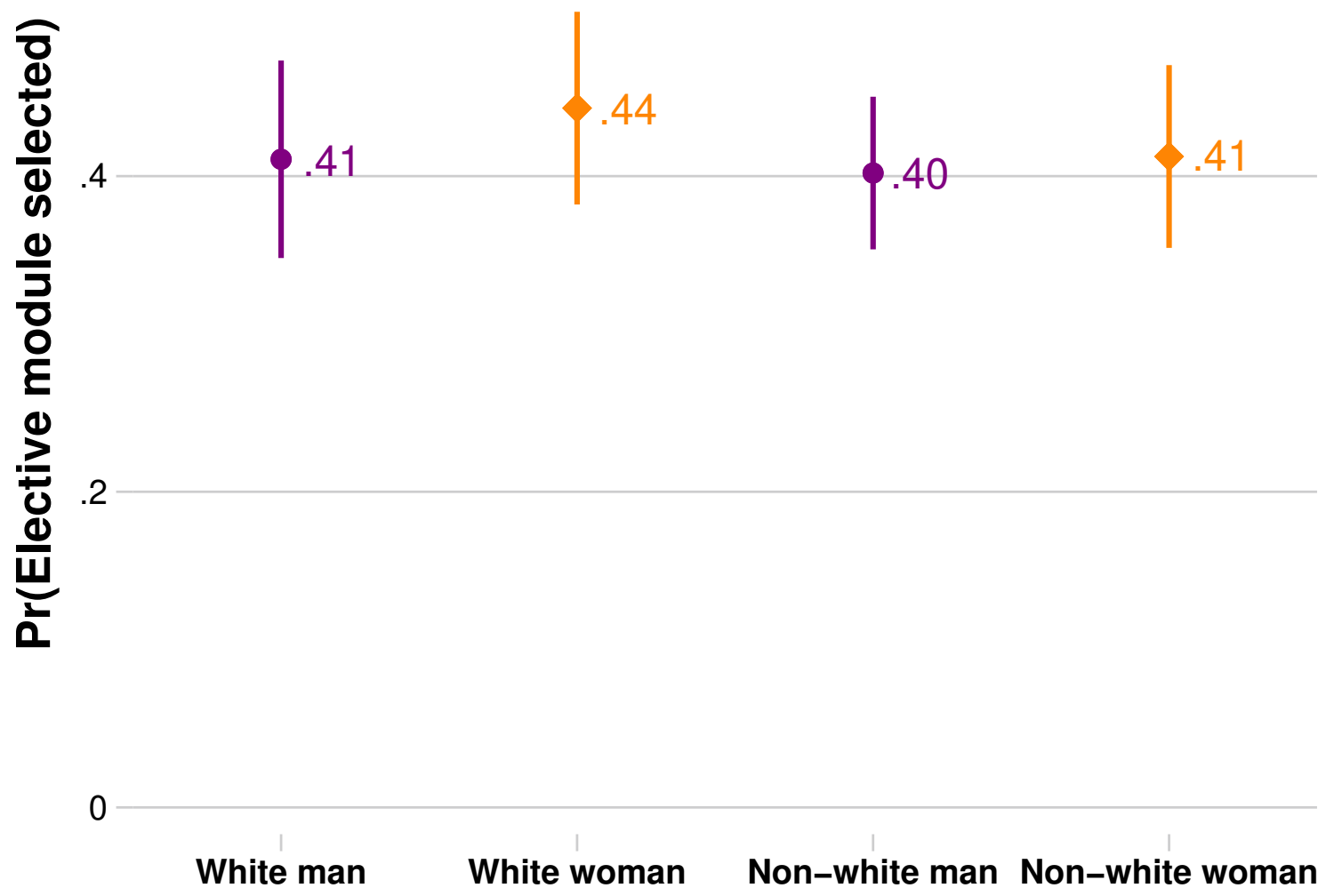

Figure 4: Conditional marginal effects

interaction effect (ACIE). Figure 4 report the mean level of favourability for modules estimating a multiplicative interaction between faculty gender and race. The results of this estimation reject hypothesis 3: there is no evidence that the (null) influence of gender or race on course preferences is moderated by value of the adjacent attribute. The highest level of favoruability is enjoyed by courses led by white women and the lowest is experienced by courses led by non-white men. Across the intersections of race and gender, however, these differences in preferences are far from being statistically distinguishable. In real terms the probability of opting-in to an elective political science course is symmetrical across the four categories. Consistent with the rejection of hypotheses one and two, there is no evidence in support of hypotheses three. 
In Figure 5 I present a tough test to analyse the sensitivity of these null results. A rich literature on the determinants and associations with support for Brexit highlight that, among other characteristics, those individuals who voted Leave are also those most inclined to harbour socially conservative values (Goodwin \& Heath, 2016), antiimmigration preferences (Dennison et al., 2020), and also be inclined to hold hostile sexist attitudes (de Geus et al., 2022). Taking identification as a Leaver or Remainer as a proxy measure for respondents' underlying ideological preferences, one can test whether individuals that are, on average, more inclined to be socially conservative and hold less sympathetic views with racial minorities, are inclined to opt-out of electives led by women or faculty of colour. Following the recommendations of Leeper et al. (2020), I test for asymmetries in the AMCE between different subgroups by comparing differences in the marginal means. Assessing the ACIE among subgroups can report misleading estimates that are frequently sensitive to decisions regarding the baseline reference category of attribute values, whereas assessing subgroup divergence based on marginal means, which report the favourability of item profiles given a concrete attribute value (Leeper et al., 2020), are not sensitive to these decisions.

Stratifying students by their Brexit sympathies as a proxy indicator for conservative socio-cultural and/or nationalist sentiment does not condition the null findings of the core attributes of theoretical interest. The mean favourability (marginal means) of a module led by a white lecturer among Remainers is .433 which is symmetrical to level of favourability among Leavers (.431). The marginal means for modules with nonwhite lecturers is statistically indistinguishable at .401 and .405 , respectively, among Remainers and Leavers. As visualised in Figure 5, similar, statistically indistinguishable effects between Remainer and Leavers are observed in the case of gender. This sensitivity test, therefore, is provides estimates consistent with the overall (null) findings). 


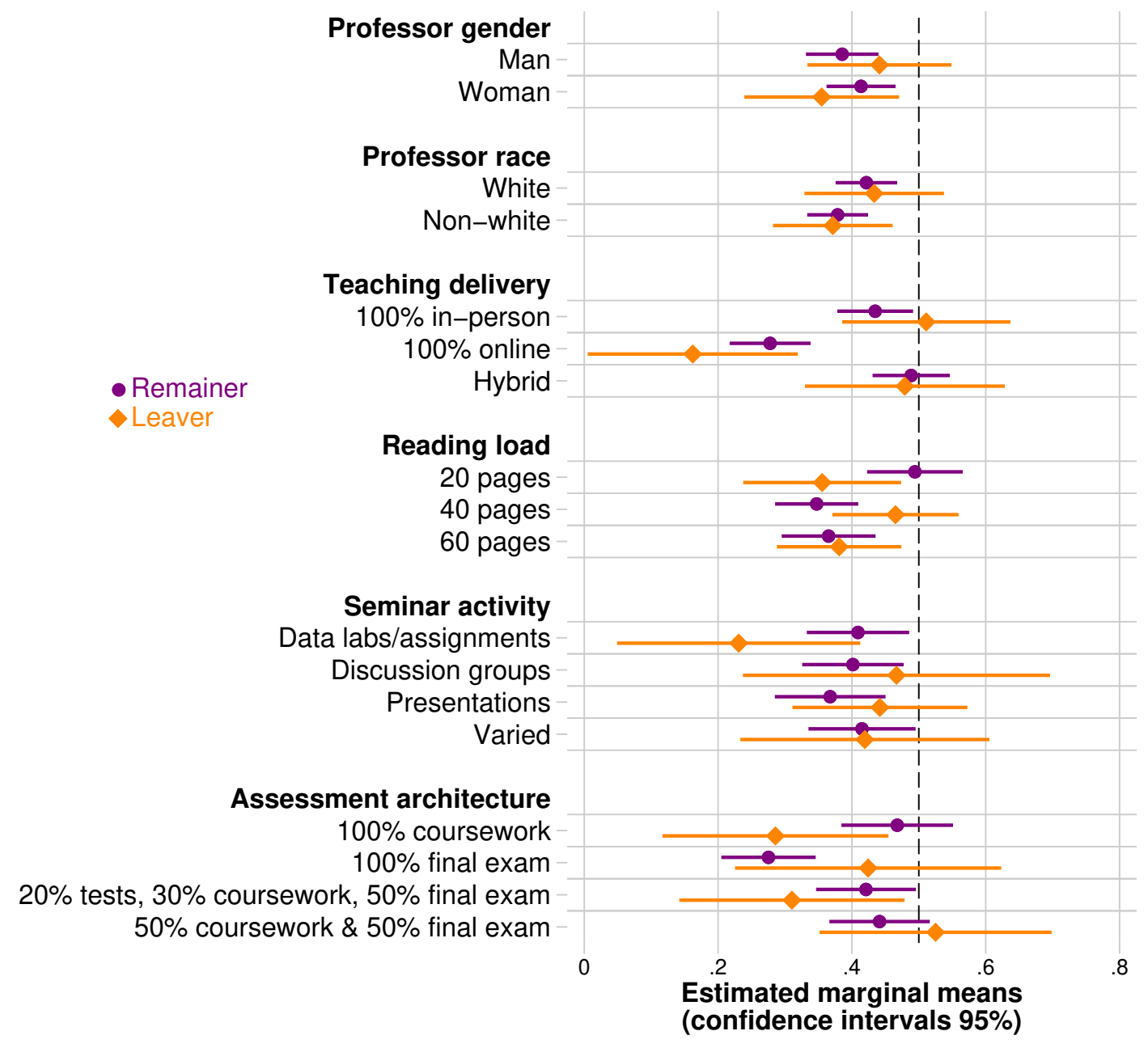

Figure 5: Marginal means (subgroups by Brexit IDs)

\section{Discussion}

Across countries and across academic disciplines, a growing body of work highlights that gender- and race-based biases exist in the classroom. This paper contributes to this literature by testing the influence of these biases at the classroom door: do students opt-in and opt-out of elective courses in response to gender- and race-based biases? Presenting the results of a conjoint experiment among first-year Politics undergraduates in the UK, I demonstrate that students place little purchase on the gender or racial profile of their professors when opting in to elective modules.

This study contributes to the literature on biases in the political science education in 
two ways. First, it breaks away from the measurement of biases ex-post and tests for their presence ex-ante actual instruction. Second, it leverages an increasingly popular experimental design that is uniquely placed to identify the influential role of concrete features among competing and often correlated multidimensional issues on individual (student) preferences for elective courses.

Whilst this experimental study is limited to a single UK institution, the University of Southampton, perhaps with the exception of the UK's most elite institutions (Oxford and Cambridge) is not significantly distinct from the Russell Group members that make up the UK's club of "leading institutions". Moreover, the conjoint design provides an excellent means of identifying the providing causal purchase to the empirical claims I make here. These findings, whilst shining an optimistic light on the (lack of) biases in elective course enrolment, present us with a new puzzle. If biases are not at play at the doorway to the classroom, this suggest that part of the explanation behind biases measured post-hoc is the result of activation processes that take place in the classroom itself.

\section{References}

Amsler, S. S., \& Bolsmann, C. (2012). University ranking as social exclusion. British Journal of Sociology of Education, 33(2), 353-371. https : / / doi.org / 10.1080 / 01425692.2011.649835

Bascow, S. A., \& Silberg, N. T. (1987). Student evaluations of college professors: Are female and male professors rated differently? Journal of Educational Psychology, 79(3), 308-314. https:/ / doi.org/10.1037/0022-0663.79.3.308

Bechtel, M. M., Hainmueller, J., \& Margalit, Y. (2017). Policy design and domestic support for international bailouts. European Journal of Political Research, 56(4), 1-21. https: / / doi.org/10.1111/1475-6765.12210 
Boliver, V. (2015). Are there distinctive clusters of higher and lower status universities in the UK? Oxford Review of Education, 41(5), 608-627. https:/ / doi.org/10.1080/ 03054985.2015.1082905

Boring, A. (2017). Gender biases in student evaluations of teaching. Journal of Public Economics, 145, 27-41. https:/ / doi.org/10.1016/j.jpubeco.2016.11.006

Bowden, R. (2000). Fantasy Higher Education: University and college league tables. Quality in Higher Education, 6(1), 41-60. https:/ / doi.org/10.1080/13538320050001063

Breitenstein, S. (2019). Choosing the crook: A conjoint experiment on voting for corrupt politicians. Research and Politics, 6(1), 1-8. https: / / doi .org / 10.1177 / 2053168019832230

Chávez, K., \& Mitchell, K. M. W. (2020). Exploring Bias in Student Evaluations: Gender, Race, and Ethnicity. PS: Political Science E Politics, 53(2), 270-274. https: / / doi. org/10.1017/S1049096519001744

Christensen, H. S., Järvi, T., Mattila, M., \& von Schoulz, Å. (2021). How voters choose one out of many: a conjoint analysis of the effects of endorsements on candidate choice. Political Research Exchange, 3(1), 1-30. https: / / doi.org / 10.1080 / 2474736X.2021.1892456

Cramer, K. N., \& Alexitch, L. R. (2000). Student Evaluations of College Professors: Identifying Sources of Bias. Canadian Journal of Higher Education, 30(2), 143-164. https: / / doi.org/10.47678/cjhe.v30i2.183360

de Geus, R., Ralph-Morrow, E., \& Shorrocks, R. (2022). Understanding Ambivalent Sexism and its Relationship with Electoral Choice in Britain. British Journal of Political Science, Online First. https:/ / doi.org/10.1017/S0007123421000612

Dennison, J., Davidov, E., \& Seddig, D. (2020). Explaining voting in the UK's 2016 EU referendum: Values, attitudes to immigration, European identity and political trust. Social Science Research, 92(1), 1-12. https:/ / doi.org/10.1016/j.ssresearch. 2020.102476 
Donnaloja, V. (2021). British Nationals' Preferences Over Who Gets to Be a Citizen According to a Choice-Based Conjoint Experiment. European Sociological Review, Online First. https:/ / doi.org/10.1093/esr/jcab034

Fan, Y., Shephard, L. J., Slavich, E., Waters, D., Stone, M., Abel, R., \& Johnston, E. L. (2019). Student Evaluations of College Professors: Identifying Sources of Bias. PLoS One, 14(2), 1-16. https: / / doi.org/10.1371/journal.pone.0209749

Gallego, A., \& Marx, P. (2017). Multi-dimensional preferences for labour market reforms: a conjoint experiment. Journal of European Public Policy, 24(7), 1027-1047. https: / / doi.org/10.1080/13501763.2016.1170191

Gelber, K., Brennan, K., Duriesmith, D., \& Fenton, E. (2022). Gendered mundanities: gender bias in student evaluations of teaching in political science. Australian Journal of Political Science, Online First, 313-319. https: / / doi.org / 10.1080 / 10361146.2022.2043241

Goodwin, M., \& Heath, O. (2016). Brexit vote explained: poverty, low skills and lack of opportunities. Joseph Roundtree Foundation.

Hainmueller, J., Hopkins, D. J., \& Yamamoto, T. (2014). Causal Inference in Conjoint Analysis: Understanding Multidimensional Choices via Stated Preference Experiments. Political Analysis, 22(1), 1-30. https:/ /doi.org/10.1093/pan/mpt024

Harris, M. B. (1975). Sex role stereotypes and teacher evaluations. Journal of Educational Psychology, 67(6), 751-756.

Leeper, T., Hobolt, S. B., \& Tilley, J. (2020). Measuring Subgroup Preferences in Conjoint Experiments. Political Analysis, 28(2), 207-221. https: / / doi.org/10.1017/pan. 2019.30

Link, A. N., Swann, C. A., \& Bozeman, B. (2008). A Time Allocation Study of University Faculty. Economics of Education Review, 27(4), 363-374. https : / / doi .org / 10. 1016/j.econedurev.2007.04.002

MacNell, L., Driscoll, A., \& Hunt, A. N. (2015). What's in a Name: Exposing Gender Bias in Student Ratings of Teaching. Innovative Higher Education, 40, 291-303. 
Magni, G., \& Reynolds, A. (2021). Voter Preferences and the Political Underrepresentation of Minority Groups: Lesbian, Gay, and Transgender Candidates in Advanced Democracies. Journal of Politics, 83(4). https://doi.org/10.1086/712142

Martin, L. L. (2016). Gender, Teaching Evaluations and Professional Success in Political Science. PS: Political Science \& Politics, 49(2), 313-319. https:/ / doi.org/10.1017/ S1049096516000275

Mengel, F., Sauermann, J., \& Zolitz, U. (2019). Gender bias in teaching evaluations. Journal of European Economic Association, 17(2), 535-566. https: / / doi.org / 10. 1093/jeea/jvx057

Miller, J., \& Chambrlain, M. (2000). Women Are Teachers, Men Are Professors: A Study of Student Perception. Teaching Sociology, 28(4), 283-298. https: / / doi.org / 10. $1017 / S 104909651800001 X$

Mitchell, K. M. W., \& Martin, J. (2018). Gender Bias in Student Evaluations. PS: Political Science E Politics, 51(3), 648-652. https:/ / doi.org/10.1017/S104909651800001X

Peterson, D. A. M., Biederman, L. A., Anderson, D., Ditonto, T. M., \& Roe, K. (2019). Mitigating gender bias in student evaluations of teaching. PLoS ONE, 14(5), 110. https: / / doi.org/10.1371/journal.pone.0216241

Reid, L. D. (2000). The role of perceived race and gender in the evaluation of college teaching on RateMyProfessors.Com. Journal of Diversity in Higher Education, 3(3), 137-152. https: / / doi.org/10.1037/a0019865

RussellGroup. (2012). Jewels in the crown: The importance and characteristics of the UK's world-class universities. Russell Group.

Sampaio, A. (2006). Women of Color Teaching Political Science: Examining the Intersections of Race, Gender, and Course Material in the Classroom. PS: Political Science \& Politics, 39(4), 917-922. https:// doi.org/10.1017/S1049096506061191

Turner, D. (2005). Benchmarking in universities: league tables revisited. Oxford Review of Education, 31(3), 353-371. https: / / doi.org/10.1080/03054980500221975 
Wagner, N., Rieger, M., \& Voorvelt, K. (2016). Gender, Ethnicity, and Teaching Evaluations: Evidence from Mixed Teaching Teams. Economics of Education Review, 54, 79-94. https:/ / doi.org/10.1016/j.econedurev.2016.06.004 
Appendix 
Table A1: Regression output from Figure 3

X $\quad \operatorname{Pr}($ Selected $)$

\begin{tabular}{|c|c|}
\hline Sex (Woman) & $\begin{array}{c}0.021 \\
(0.035)\end{array}$ \\
\hline Race (non-white) & $\begin{array}{l}-0.020 \\
(0.036)\end{array}$ \\
\hline Del: $100 \%$ online & $\begin{array}{c}-0.199 * * * \\
(0.042)\end{array}$ \\
\hline Del: hybrid & $\begin{array}{c}0.041 \\
(0.041)\end{array}$ \\
\hline Read: 40 pages & $\begin{array}{c}-0.109^{* * * *} \\
(0.038)\end{array}$ \\
\hline Read: 60 pages & $\begin{array}{c}-0.122^{* * * *} \\
(0.043)\end{array}$ \\
\hline Sem: discussions & $\begin{array}{c}0.033 \\
(0.044)\end{array}$ \\
\hline Sem: presentations & $\begin{array}{c}0.041 \\
(0.046)\end{array}$ \\
\hline Sem: varied & $\begin{array}{c}0.037 \\
(0.048)\end{array}$ \\
\hline Assess: $100 \%$ exam & $\begin{array}{c}-0.158^{* * * *} \\
(0.050)\end{array}$ \\
\hline Assess: Mixed & $\begin{array}{l}-0.059 \\
(0.048)\end{array}$ \\
\hline Assess: $50-50$ split & $\begin{array}{l}-0.015 \\
(0.051)\end{array}$ \\
\hline Constant & $\begin{array}{c}0.560^{* * *} \\
(0.059)\end{array}$ \\
\hline Observations & 936 \\
\hline R-squared & 0.076 \\
\hline
\end{tabular}


Table A2: Regression output based on 7-point (0-6) response scale

(1)

X Probability (0-6)

Sex (woman) $\quad 0.023$

Race (non-white) $\quad 0.007$

$(0.089)$
0.007

$(0.082)$

Del: $100 \%$ online $\quad-0.939^{* * *}$

(0.155)

Del: Hybrid $\quad-0.204$

$(0.127)$

Read: 40 pages $\quad-0.425^{* * *}$

$(0.114)$

Read: 60 pages $\quad-0.439^{* * *}$

(0.106)

Sem: discussions $\quad 0.072$

$(0.144)$

Sem: presentations $\quad-0.043$

$(0.156)$

Sem: varied $\quad-0.005$

$(0.108)$

Assess: $100 \%$ exam $\quad-0.895^{* * *}$

(0.160)

Assess: Mixed $\quad-0.415^{* *}$

Assess: $50-50$ split $\quad-0.376^{* * *}$

(0.138)

Constant $\quad 4.628^{* * *}$

(0.179)

Observations $\quad 936$

R-squared $\quad 0.135$

Robust standard errors in parentheses ${ }^{* * *} \mathrm{p}<0.01,{ }^{* *} \mathrm{p}<0.05,{ }^{*} \mathrm{p}<0.1$ 
In Figure A1 I test whether individuals task iterations (i.e., the number of the iteration of the 6 iterations completed by an individual respondent) influences the results. As demonstrated, the null effects of the two theoretically important variables is consist ant and largely stable across iterations of the forced comparisons.

\section{Testing for potential influence of iteration rounds}

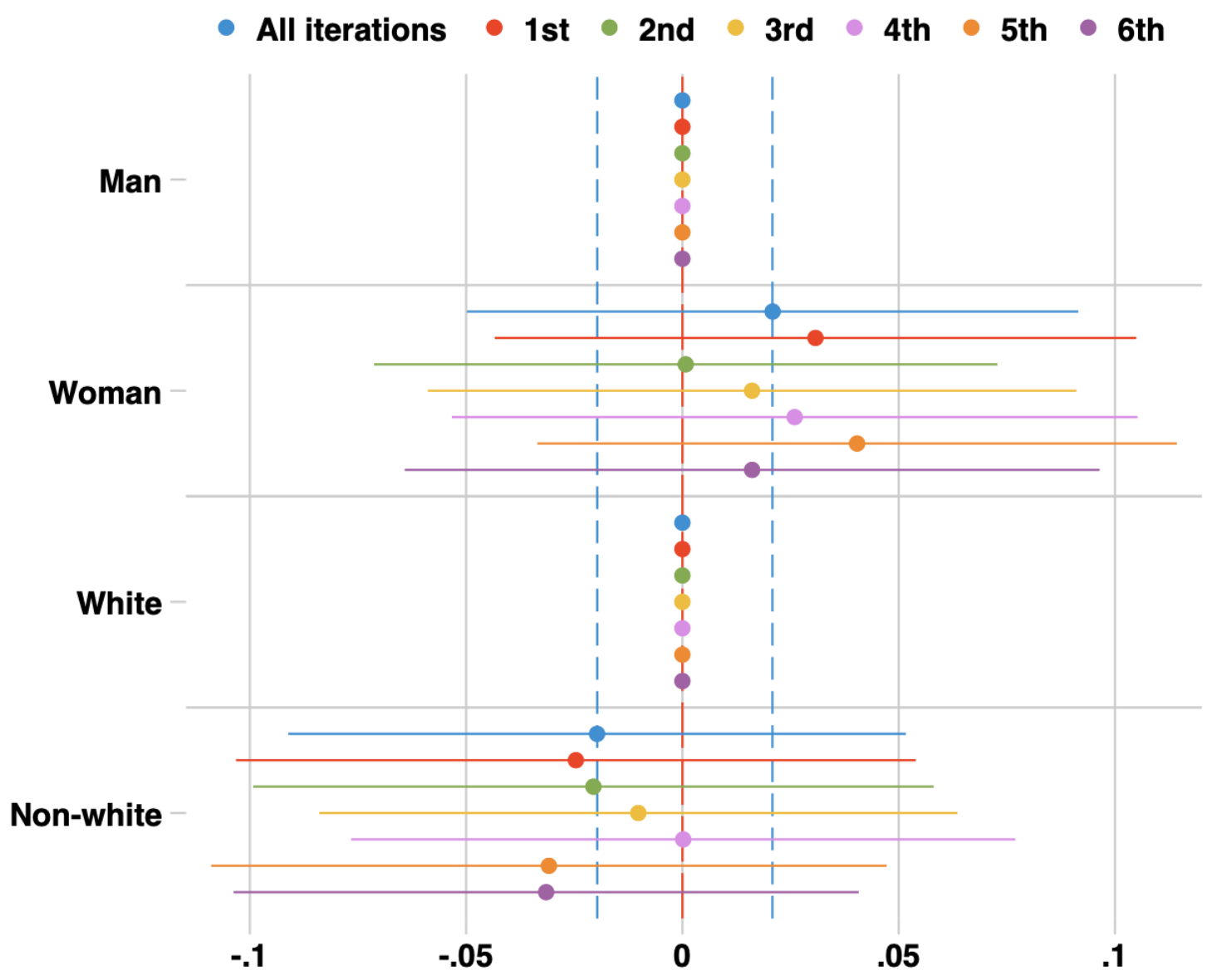

Figure A1: Robustness test: iterations comparison 